Unusual case of central alveolar

hypoventilation. Lessons learned from

ventilatory management of patients with

alveolar hypoventilation in critical care

conditions

To the Editor

In this article, authors reported an unusual case of central alveolar hypoventilation in a young patient with a body mass index (BMI) of $21 \mathrm{~kg} / \mathrm{m}^{2}$ and with a genetic testing negative for $\mathrm{PHOX} 2 \mathrm{~B}$ gene mutation. ${ }^{1}$

In this unusual case, we have some comments regarding ventilatory management:

1) During the first and second extubation, the authors do not report post-extubation partial pressure of carbon dioxide ( $\mathrm{pCO} 2$ ) levels and whether the patient received non-invasive ventilation (NIV). The usefulness of NIV in patients with hypoventilation syndrome after acute events that follow chronic hypercapnic respiratory failure is well documented. ${ }^{2}$ On the other hand, tracheostomy may be a valid treatment for patients who cannot tolerate NIV, have poor NIV compliance, or cannot achieve a successful extubation.

2) Regarding ventilatory management, the authors did not report data on ventilatory mechanics; especially exhaled tidal volumes, minute volume and respiratory rate, while the patient underwent volume control-synchronized intermittent mandatory ventilation. This information is useful in congenital central hypoventilation syndrome (CCHS), which is characterized by alveolar hypoventilation; modest hypoventilation occurs during REM sleep and variable hypoventilation occurs during wakefulness. However, hypoventilation results from persistently low tidal volume with variations in minute ventilation, mainly as a result of respiratory rate fluctuations. ${ }^{3}$

3) About polysomnography analyses, the authors reported high values of $\mathrm{PaO}_{2}$ and $\mathrm{SaO}_{2}$ during polysomnography testing: $\mathrm{PaO}_{2}: 232 \mathrm{~mm} \mathrm{Hg}$ during the first study and $160 \mathrm{~mm} \mathrm{Hg}$ during the second study, (both with $\mathrm{SaO}_{2}$ above 98\%). However, the diagnosis of CCHS is suspected when polysomnography testing demonstrates hypoxia and hypercapnia that are worse during sleep than during wakefulness, and confirmed by a $P H O X 2 B$ mutation in genetic testing.

4) Regarding hospital stay, the authors did not report length of hospital stay and mechanical longterm ventilator use, neither the presence of nosocomial infection nor germ isolation. Currently, the role of nosocomial infections in the intensive care unit stay is well studied and influences treatment and progression of disease. ${ }^{4}$

We highlight the importance of the presentation of this unusual case and believe that the considerations exposed should be taken into account to clarify concepts that might be overlooked in clinical practice.

Killen H. Briones-Claudett
Universidad Católica de Santiago de Guayaquil
Guayaquil, Ecuador
ORCID ID: orcid.org/0000-0002-7778-0362
Michelle Grunauer
School of Medicine,
Universidad San Francisco de Quito
Quito, Ecuador

\section{Reply from the Author}

We thank Briones-Claudett \& Grunauer for their interest and comments on our article "Unusual case of central alveolar hypoventilation". ${ }^{1}$

Later-onset congenital central hypoventilation syndrome (CCHS) usually have the mildest hypoventilation, presenting primarily after exposure to respiratory depressants or severe respiratory infection, and are managed with nocturnal ventilatory support only as they have hypoventilation during non-rapid eye movement (REM) sleep while adequate ventilation is maintained during wakefulness. ${ }^{5}$ The diagnosis is made based on clinical findings of alveolar hypoventilation and autonomic nervous system dysfunction in the absence of primary pulmonary, cardiac, or neuromuscular disease, or a causative brain stem lesion that can account for the entire phenotype; and identification of a pathogenic variant in $P H O X 2 B$. The patient in this case report had clinical findings consistent with the diagnosis of late onset CCHS; however, she tested negative PHOX $2 B$ gene. Approximately $10 \%$ of individuals with CCHS are heterozygous for a missense, nonsense, or frame shift mutation in the $P H O X 2 B$ gene. ${ }^{6}$ Pending further detailed DNA sequencing, she is considered to have idiopathic central alveolar hypoventilation. Following the 2 extubation trials, she developed acute deterioration in level of consciousness, became drowsy and unresponsive, brady cardic and desaturated down to 70 's, arterial blood gas were taken on $100 \%$ NRM preceding the reintubation in the 2 occasions (Table 1 ).

Non-invasive ventilation was not tried due to low GCS and hemodynamic instability. Both reintubations occurred during sleep. Bi-level positive airway pressure 
Table 1 - The 2 arterial blood gas intubation.

\begin{tabular}{lll}
\hline ABG before the $1^{\text {st }}$ intubation & $\mathrm{pH}$ & 7.14 \\
& $\mathrm{PaCO} 2$ & $107 \mathrm{mmHg}$ \\
& $\mathrm{HCO} 3$ & $27 \mathrm{mmHg}$ \\
& $\mathrm{PaO} 2$ & $111 \mathrm{mmHg}$ \\
& $\mathrm{SO} 2$ & $99 \%$ \\
ABG before the $2^{\text {st }}$ intubation & $\mathrm{pH}$ & 7.19 \\
& $\mathrm{PaCO} 2$ & $65 \mathrm{mmHg}$ \\
& $\mathrm{HCO} 3$ & $20 \mathrm{mmHg}$ \\
& $\mathrm{PaO} 2$ & $122 \mathrm{mmHg}$ \\
& $\mathrm{SO} 2$ & $99 \%$ \\
\hline ABG - arterial blood gas, PaCO2 - partial pressures of carbon \\
dioxide, HCO3 - bicarbonate, PaO2 - partial pressures of oxygen, \\
SO2 - oxygen saturation \\
\hline
\end{tabular}

was used for weaning off nocturnal ventilation and for long term management following the resolutuion of the acute event. During volume control synchronized intermittent mandatory ventilation, $\mathrm{Vt}$ was 400 , respiratory rate was set at 12 , positive end-expiratory pressure was 5, pressure support was 10 , fraction of inspired oxygen $(\mathrm{FiO} 2)$ was $30 \%$, exhaled tidal volume was ranging $350-560 \mathrm{ml}$. This is consistent with the central hypoventilation where the tidal volume with resultant effect on minute ventilation varies between sleep and wakefulness, being lowest in non-REM sleep in CCHS, but it is also abnormal during REM sleep and wakefulness, although usually to a milder degree sleep.

During the polysomnography conducted in the ICU,the patient showed evidence of hypoventilation and high PCO2 which was detected promptly after 45 minutes in first trial and 10 minutes in the second) and patient was connected back to the ventilator to prevent further Oxygen desaturation.( hypnogram1)

The patient had prolonged hospital course.The total hospital length of stay was 113 days, out of which 97 days were spent in the intensive care unit. She was mechanically ventilated, mostly at night for 65 days.
Tracheostomy and later diaphragmatic pacing were performed to facilitate weaning from mechanical ventilation. Her course in the intensive care unit was complicated with one episode of ventilator associated due to Klebsiella pneumoniae that was treated with appropriate antibiotics.

This unusual case alerts physicians to consider central alveolar hypoventilation in young patients presenting with type 2 respiratory failure following respiratory infections particularly during sleep.

$$
\begin{array}{r}
\text { Hadil AK. Alotair } \\
\text { Department of Critical Care Medicine } \\
\text { King Saud University } \\
\text { Riyadh, Kingdom of Saudi Arabia } \\
\text { ORCID ID: orcid.org/0000-0002-1385-6268 }
\end{array}
$$

\section{References}

1. AlOtair HA, Alzeer AH, Abdou MA, Qasrawi SO. Unusual case of central alveolar hypoventilation. Saudi Med J 2018; 39: 305-310.

2. Heinemann F, Budweiser S, Dobroschke J, Pfeifer M. Noninvasive positive pressure ventilation improves lung volumes in the obesity hypoventilation syndrome. Respir Med 2007; 101: 1229-1235.

3. Berry-Kravis EM, Zhou L, Rand CM, et al. Congenital central hypoventilation syndrome: PHOX2B mutations and phenotype. Am J Respir Crit Care Med 2006; 174: 1139-1144.

4. Group SCCT. Incidence of severe sepsis and septic shock in German intensive care units: the prospective, multicentre INSEP study. Intensive Care Med 2016; 42: 1980-1989.

5. Weese-Mayer DE, Berry-Kravis EM, Ceccherini I, Keens TG, Loghmanee DA, Trang H. An official ATS clinical policy statement: Congenital central hypoventilation syndrome: genetic basis, diagnosis, and management. Am J Respir Crit Care Med 2010; 181: 626-644.

6. Sateia MJ. International classification of sleep disorders-third edition: highlights and modifications. Chest 2014; 146: 1387-1394. 